\title{
Means-End Chain Model Framework for Measuring Housing Environment Choice Behavior
}

\author{
Zinas Bako Zachariah and Mahmud Bin Mohd Jusan \\ Department of Architecture, Universiti Teknologi Malaysia (UTM), Malaysia
}

\begin{abstract}
Housing and housing space has been a place for personal development, recreation and self accentuation. The need for housing and housing space quality can therefore not be overemphasized. The need for housing remains a constant index for all societies through the ages. Housing is a complex and heterogeneous product in its setting, the cognitive structures of housing users for housing attributes is also complex as well as their choice behaviors. Means-End Chain (MEC) model has been found to be very effective and potent in measuring these complexities. This conceptual paper explores from literature the MEC model and attempts to propagate its use as a research model for housing research, environment-behavior studies and person-environment congruence. It also presents the methodology employed by MEC for data collection and data management. It will suggest an extension to the traditional methodology that MEC utilizes. The possibility of extending the previous methods and their applicability in design process is herein presented; and to make a case for the usability of MEC model as a research tool for housing researchers. In dealing with user preference of housing, there is a need for research for a development of a technological tool for the identification of user needs and preference, and the kind of decision support that are required to identify these needs.
\end{abstract}

Key words: Means-End Chain, laddering technique, housing preference and choice, stated models, revealed models.

\section{Introduction}

Means-End Chain (MEC) model has been used extensively for research in merchandized products field for many years, but in the past few years it has been gaining its usability interest among housing environment researchers. One of the more relevant aspects of marketing research from the scientific as well as the operative standpoint is the comprehension of consumer decision-making processes. However, the methods employed to study consumer behavior are often unsatisfactory due to the lack of a tool linking consumers' knowledge of product characteristics and their needs, hence their own characteristics. The means-end chain (MEC) model is a conceptual tool which allows you to understand how consumers perceive the self-relevant outcomes of product use and consumption [1-4].

Corresponding author: Zinas Bako Zachariah, $\mathrm{PhD}$ candidate, research fields: user centered architecture (housing environment choice behavior). E-mail: bzinas@gmail.com.
The Means-End Chain (MEC) model [5] originally developed by Jonathan Gutman for merchandized products, which application in the field of architecture and urban design has been very useful and successful in the past few decades [6], is the framework within which this paper is anchored. MEC utilizes the laddering technique for data collection, analysis and interpretation [7, 8]. Many different approaches to measuring user preferences have been suggested or developed, ranging from simple direct questioning of respondents to sophisticated measurement approaches such as conjoint analysis, which allows researchers to test the assumptions underlying their measurement approaches. Conjoint analysis is a measurement approach in which users are requested to express their preference for attribute profiles, which are constructed according to an experimental design [9]. There are basically two broad modeling approaches to measure housing choice and preference-the revealed housing choice models and the stated housing preference and choice models. Revealed models are based on 
observational data of households' actual housing choices in real markets; while stated models are based on the premise that observed choices will also reflect the joint influence of preferences, market conditions, and availability [10]. This paper examines and outlines the methodological and theoretical framework of housing preferences and choices, based on the theory of means-end chain (MEC).

Previous MEC applications in the field of architecture and urban design have been very useful and successful and MEC has been found to be a good research tool for measuring housing choice and motivational reason(s) of the housing environment user $[11,12]$.

\subsection{Aim of This Paper}

This Conceptual paper aims at presenting the conceptual framework of MEC research model, and propagates and recommends its use for investigating housing choice behavior in housing environment research.

\section{Theoretical Framework of MEC Theory}

This section provides a brief overview of theoretical framework of MEC model used in research process. It will explain what MEC is, its underlying concept, its variables, and the methodology for data collection, analysis and interpretation

\subsection{The Means-End Chain (MEC) Model}

MEC model has a long research history. Gutman [5] first introduced the concept, with a focus on qualitative in-depth understanding of consumer motives. This qualitative approach was used to identify and represent the content and structures of consumer models for products and brands. Reynolds and Gutman [3] made MEC model well-accepted by providing a hands-on description of how to conduct, analyze and use MEC interviews [13]. Kaciak and Cullen [14] assert that MEC has been a popular and ever-evolving research domain since its introduction.
Gutman's MEC theory [5] was inspired by research from Rokeach [15], and Yankelovich [16] who showed that values direct people's behavior in all aspects of their lives [17]. Although MEC original purpose was for linking consumers' values to their choice behavior in marketing and consumer research, it is becoming popular in other areas [6] like architecture, urban design, advertising, information technology, and organizational management [18].

Gutman [5] defines MEC as a model that seeks to explain how a product or service selection facilitates the achievement of desired end states. MEC links sequentially products' attributes (A) to consequences of product use $(\mathrm{C})$ and to individuals' personal values (V). The resultant A-C-V sequence that forms is called means-end chain or ladder. Coolen et al. [19] view MEC as a model that relates the choice of a good (defined as a collection of attributes) to its contribution to achieving objectives and values. They explained that “means” are objects (products) or activities in which people engage, e.g., running, reading, cooking, etc., and "end" is valued states of being such as happiness, security, and accomplishment. The essential idea in MEC theory is that consumers choose the actions which produce the desired consequences and which minimize the undesirable consequences. Reynolds and Whitlark [20] paradoxically stress that while a means can be an end, an end can also be a means. Meesters [21] posits that in order to make the right choice between the different goods with different consequences, the consumer must learn which good possess the attributes producing the desirable consequence.

In the means-end chain model, products are thus not chosen and purchased for themselves or their characteristics, but rather for the meaning they engender in the mind of prospects [3]. In this way products, though selected for fairly concrete features, such as their characteristics and attributes (e.g., proportion of fat, color, origin, production method), and for the benefits which they are capable of providing-functional or psychosocial consequences 
(e.g., a healthy and tasty diet)-are in fact perceived subconsciously as aimed at and connected with the achievement of individual goals [2].

\subsection{Assumptions of MEC}

The original MEC model by Gutman [5] is based on four assumptions. Firstly, it assumes that objectives and values influence choice processes; secondly, it assumes that people can keep track of the enormous diversity of goods by grouping them in sets or classes so as to produce the complexities of choice; thirdly, it assumes that behavior of consumers has consequences, although these consequences do not have to be for everybody; and fourthly, it assumes that consumers learn to associate particular consequences with particular behaviors [5, 6, 8].

\subsection{Conceptual Structure of MEC Model}

The variables or constructs of the original structure of MEC model [5] are attributes, consequences and values (Fig. 1). The linkage between values and consequences is of essential importance in the MEC model. Coolen et al. [19] give the linkages as, firstly, that a certain good must be consumed or used to realize a desirable consequence; secondly, it is the linkage between consequences and the attributes of goods.

It explores the connection between consumer and product through the construction of a simple associative network between concrete and abstract product attributes, functional and psychosocial consequences linked with product use and, finally, consumers' instrumental and terminal values. Product attributes are but means through which consumers achieve their ultimate values, ends, via the positive consequences or benefits accruing from the attributes. In other words, goods/services are seen as means to satisfy needs that are conscious to a varying degree.

The conceptual model of MEC theory can be summarized in the following propositions [2]: firstly, the subjective knowledge about consumers' goods and services is organized in associative networks; secondly, the concepts in these networks that are relevant for consumer decision-making are attributes of products, consequences of product use, and consumers' values; thirdly, attributes, consequences and values are ordered hierarchically; and fourthly, the structure of consumers' knowledge about goods and services influences relevant consumer behavior [2, 8].

Olson and Reynolds [22] proposed some modifications on Gutman [5] model, broadening the chain levels. The broadened model recommends that the attributes be sub-divided into concrete and abstract; consequences into functional and psychological; and personal values into instrumental and terminal [4, 23]. The broadened conceptual framework of MEC model is as illustrated in Fig. 2.

\subsubsection{Attributes}

Attributes are concrete (e.g., color) or abstract (e.g., taste) product characteristics. The New Webster's dictionary [24] defines attributes as "a quality proper to a characteristic of a person or thing”. Valette-Florence and Rapacchi [4] view attributes as features or aspects of products or services. Gengler et al. [25] perceive them as relatively concrete meanings that represent physical or perceptible characteristics in a product. According to Botschen et al. [23], attributes are characteristics of products, services, or behavior that are preferred or sought for by consumers. While agreeing to all these definitive views, attributes can be seen as the intrinsic and physical features, properties or characteristics that define a product or person.

Attributes are of two levels: concrete attributes and abstract attributes [22]. Concrete attributes are defined as the directly perceptible physical characteristics of a product, e.g., price, color, and weight [26], while abstract attributes are relatively intangible characteristics, such as style and brand [27], or perceived value or importance [23]. Jusan [7] classifies



Fig. 1 Structure of MEC [5]. 


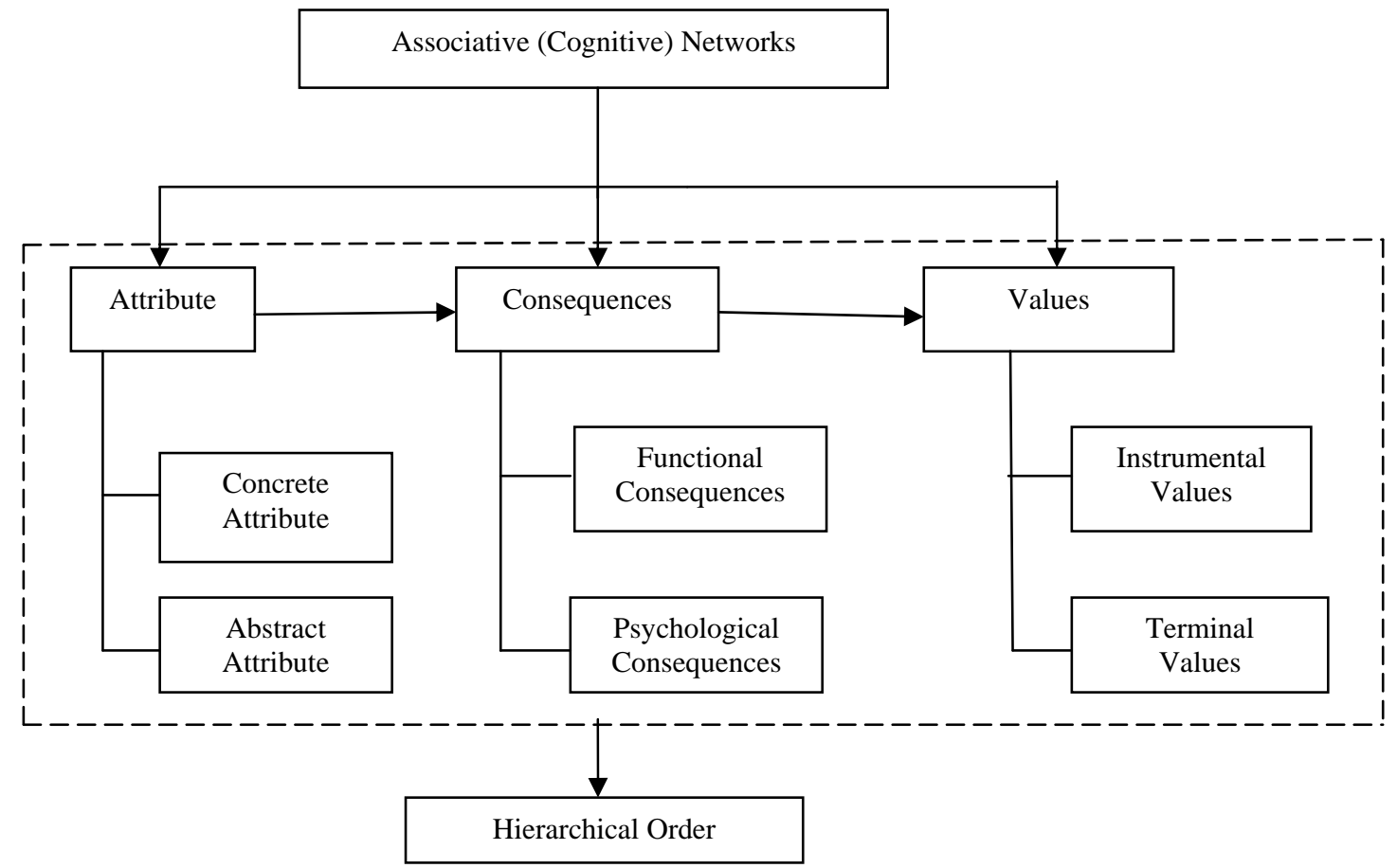

Fig. 2 Broadened structure of MEC model [5, 11, 12, 22].

concrete attributes into two groups, namely, element and relationship, as it relates to housing. He sees abstract attributes as "meanings" perceived by the housing user.

\subsubsection{Consequences}

Consequences are defined as "that which follows something and arises from it" [24]. Coolen and Hoekstra [8] view consequences as every direct or indirect result of a person's behavior. They are the effects that are produced by a given product; the characteristics that are less directly perceptible in a product or brand, and are the result of various attributes combinations [26]. Lin [27] posits that consequences are what the consumer feels after consuming the product, this might be a positive feeling e.g. benefits, or a negative feeling, e.g., perceived risks. In specific situations, Valette-Florence and Rapacchi [4] posit that they represent behaviors.

Consequences are at the intermediary level in the chain, and have a more abstract meaning that reflects perceived benefits [25]. Jusan [7] relying on Gutman [5] states that there are two categories of consequences in Gutman's MEC, namely, functional consequences and abstract consequences. He posits that functional consequences refer to practical benefits and performance outputs, while abstract consequences are feelings or social considerations. Consequences may be physiological (satisfying hunger, thirst, or other physiological needs) or psychological (self-esteem, improve outlook in the future) or sociological (enhance status, group membership) in nature. They may occur directly (e.g., buying a new dress, I feel better) or indirectly (e.g., because I feel better, people react more favorable to me) [5].

\subsubsection{Values}

Values are at the most abstract level in the chain. Rokeach [15] defines values as enduring benefits that a particular mode of conduct or particular end-state of existence is personally and socially preferable to alternative modes of conduct or end-states of existence. They are the benefits and relatively stable conditions that have a strong emotional impact, e.g., security, happiness, fun, and enjoyment [26]. Dibley and Baker [28] posit that values determine, regulate, and modify relationships between individuals, organizations, institutions, and societies. According to 
Valette-Florence and Rapacchi [4], personal values provide general guidance and are part of our lives. Schwartz [29] sees values as "desirable translational goals, varying in importance that serves as guiding principles in the life of a person or other social entities". Values are life's drivers that cause an individual to function in all his actions. They are propellers for preferences and choices in life. They are the reasons for the affection a person has for whatever he has affection for. They coordinate most of a person's behavioral traits in life. They are the things that direct and shape our inner motivations and choices in life.

Schwartz [29] assesses that values can influence behavior in the following ways: firstly, values contribute to our ability to take a standpoint with respect to political and social questions; secondly, values may be used in the assessment of ourselves and others; thirdly, values play a central part in comparison processes; and fourthly, values may form criteria for all the evaluation of the opinions, attitudes and actions of ourselves and others [8]. In order to be able to live and function in a social environment, individuals and groups transform the needs that are inherent to human existence into specific values $[8,19]$. Schwartz [30] states that the central role of values in the human cognitive system stems from three types of human need: the needs of the individual as a biological system; the demands set by coordinated social interaction; and the demands which stem from the functioning and survival groups. From these fundamental human needs, Schwartz [29, 30], empirically derives ten universal, motivational value domains. These domains are: (1) power (social power, wealth); (2) achievement (success, ambition); (3) hedonism (pleasure, enjoying life); (4) stimulation (daring, exciting life); (5) self-direction (independence, curiosity); universalism (social justice, unity with nature); (7) benevolence (helping, true friendship); (8) tradition (modesty, devoutness); (9) conformity (politeness, self-discipline); (10) security (family security, cleanness) [7, 8, 19]. Each individual strives for values belonging to each of these domains.

According to Rokeach [31], the values will not be of the same importance for every individual. He clarifies that individuals organize and structure their values so that they are in a position to choose from alternative objectives and actions, and are able to resolve potential conflicts. He calls this configuration of values as a value system, which Coolen et al. [19] define as "a learned and organized entity of principles and rules that helps people in their choice between alternatives, to resolve conflicts, and make decisions”. They further allude that people's choice behavior is determined by a combination of both the values activated by the choice situation. Rokeach [31] subdivided values into instrumental and terminal values. Terminal values represent the final states of existence, i.e., they are the goals we seek in life, such as peace, self-achievement, and prosperity, and instrumental values are ways of behaving that lead to terminal values, such as ambition and resourcefulness that might be necessary for achieving prosperity $[6,7]$. In a choice situation, various values will be activated in a person's value system. It is unlikely that people will be able to act in agreement with all of the activated values simultaneously [31]. Blaauboer and Mulder [32] contrast the choice behaviors of two individuals with similar backgrounds by adjudging that two individuals in the same phase of their life course (of the same age or both at the end of their educational career) can make different choices on family formation, because they have different preferences or attitudes. On the whole, it can be concluded that values define a person in the totality of his behavior, attitude, goal direction and general orientation of life. Any choice therefore that an individual makes, is navigated and oscillated within the pendulum of life's values [11].

\section{Methodology in MEC}

The method used for data collection in MEC is known as laddering. 


\subsection{Laddering Technique}

Laddering refers to an in-depth one-on-one interviewing technique used to develop an understanding of how consumers translate the attributes into meaningful associations with respect to self, following means-end theory [3, 5]. Reynolds and Whitlark [20] describe it as an interviewing technique that can be used to elicit means-end connections and attribute-consequence-value networks people use when making decisions about life's endeavors. It is qualitative in nature-utilizing a semi-structured interviewing tool aimed at eliciting responses from respondents' perception on the attributeconsequence-value (A-C-V) elements [7]. Reynolds and Gutman [3] assess that laddering involves a tailored interviewing format using primarily a series of directed probes, typified by the "why is that important to you?" question, with the express goal of determining sets of linkages between the key perceptual elements across the range of attributes (A), consequences (C), and values (V). Costa et al. [33] describe it as face-to-face, individual, in-depth, semi-structured interviews aiming at the elicitation of the attribute-consequence-value associations consumers hold regarding the object(s) under study.

Laddering technique was first introduced in the 1960s by clinical psychologists as a method of understanding people's core values and beliefs [34]. Various researchers, Tania et al. [6], Costa et al. [33], Grunert and Grunert [1], and Reynolds and Gutman [3], agree that the laddering technique was developed by Dennis Hinkle [35] (PhD dissertation), as a means of modeling people's belief structures; and the term "laddering” was coined by Bannister and Mair [36] who extensively used the technique in their research.

\subsection{Prioritized Questioning Structure of Laddering Technique}

In conducting laddering interviews, the right questions may be difficult to come by, and the interviewee may be nervous or uncomfortable with the line of question. To ease this dilemma, Wansink [37] suggests and sums up the main points that should be prioritized in a laddering interview as: (1) ask questions that can reveal personal reasons; (2) ask questions that lead the person to think and answer with a sentence, not just responding with a "yes" or "no"; (3) keep asking "why"; (4) question people's reasons for their answers; (5) allow the questioning to flow; (6) ask questions that give respondents' free reign to answer the questions as they feel is more appropriate; and (7) watch the people's facial expressions as they answer the question and listen to the tone of their voices.

\subsection{Conceptual Framework of Laddering Technique}

Laddering technique is generally framed in seven phases for the purpose of data collection, analysis and interpretation. The following phases have been outlined: (1) elicitation of the attributes; (2) selection of the functional attributes; (3) elicitation of the attribute levels; (4) performing laddering interviews; (5) determination and coding of means-end chains; (6) aggregation: construction of hierarchical value map (HVM); and (7) analysis and interpretation of the HVM $[7,8]$. These phases are for the purpose of measuring and analyzing the various elements and the linkages between them in MEC.

Gengler and Reynolds [38] sum the steps for the laddering analysis and interpretation as follows: (1) data reduction (data conversion into separated phases); (2) content analysis of the elements selected in the previous steps; (3) summation of relations in content codes, resulting in an implication matrix of all paired relationships; and (4) construction of a diagram to meaningfully represent the main implication of the study-the HVM. Several researchers [3, 6, 8, 33, 38, 39] are unanimous that content analysis tool is the core of the analytical procedure in a means-end study.

Tânia et al. [6] outline the following concept for analyzing data that originated from the laddering interviews: the first step is the reduction of data originated from interviews. These phrases are basic 
elements in which the subsequent analyses are based. To identify the elements that better represent the expressed concepts by each person individually. The results are categorized under codes. Each code is identified as an attribute, consequence, or value, which means that all data are categorized into elements. There is a common coding for all products involved into the laddering interviews.

Following the coding step, an implication matrix is generated which serves as a method of bridging the gap between the qualitative and quantitative aspects of the technique. A HVM is then constructed on the basis of the results of the implication matrix. It shows a graphic presentation of all the most frequently mentioned attributes, consequences, and values, and it consists of a series of nodes, connected by lines, representing the aggregate of the respondents' ladders. The laddering results can be used to create an HVM summarizing all interviews across individuals, which is interpreted as representing dominant perceptual orientations, or "ways of thinking" with respect to the product category [6]. For details of examples of coding, implication Matrix and HVM, see Ref. [6].

\subsection{MEC and Housing Choice \& Preference}

Housing is a complex and heterogeneous product in its setting, the cognitive structures of housing users for housing attributes are also complex as well as their choice behaviors. Housing preferences and choices operate within the framework of preferences and choices for housing attributes. In any preference and choice activity, there are underlying motivations that make it possible for an individual to choose from available alternatives within a given product field [11, 12]. Choices are versions of our life expressions. We become versions of who we are based on the different choices that we make [12]. Zinas and Jusan [11, 12] state that preferences and choices are lifetime phenomena, and that every person lives and operates within the framework of choosing from alternatives of life's endeavors. These choice and preference activities, they further said, are dynamic in modus operandi. Molin et al. [40] state that choices are understood to echo preferences. The Means-End Chain (MEC) model has been found in its application to successfully handle and measure these complexities in housing research. Even though housing brands are hardly known, however, the housing attributes are well known [8], however to measure housing choice and preference behaviors using the MEC model some measurement elements or approaches can be suggested to handle the quantitative aspect that the laddering interviewing technique that MEC models utilizes for data gathering is unable to do. This will also serve as an extension to MEC model [11, 12].

The conceptual steps outlined by several researchers [3, 6-8, 33, 38], for eliciting relevant attributes in MEC for laddering interview, seem to have elements for both quantitative and qualitative research methods with respect to measuring housing choice behaviors particular in hypothetical situations [11, 12]. They further clarified that in a situation where the relevant attributes are known like it is for housing; the first two steps should not be used as posited by Coolen and Hoekstra [8]. According to Coolen and Hoekstra [8], this method is often used where relevant attributes are unknown, and one is dealing with a homogeneous product field. They stressed that housing is an extremely heterogeneous product which brands are hardly known, even though its relevant attributes are known. In their research, they employed the Repertory Grid as a tool with which they compiled and presented to their respondents 45 housing attributes for them to select or choose from the list the attributes they preferred, thereafter, the laddering interview was conducted.

Zinas and Jusan [12] posit that in a hypothetical or intended housing choice and preference research situation, some other instruments like questionnaire can be employed to elicit the respondents' attributes choice and preference before the laddering interview in MEC can be conducted. They averred further that the 
conceptual framework of stated preference and choice model approach presents a potential for this to be achieved. Adamowicz et al. [41] posit that stated models are choice-based approaches and method of preference elicitation that presents to respondents one or more choice sets of two or more alternatives and asks that they indicate their most preferred alternative. According to Orzechowski [9], the alternatives of interest can be presented through a questionnaire by paper-and-pencil, but other means of presentation such as multi-media can also be used. He clarifies further that the major advantage of this model is that it allows you to measure preference of choice behavior for products that do not exist yet. Abley [42] asserts that the data generated from this kind of survey proved far easier to analyze, and allowed greater prediction of market shares. Merino-Castello [43] outlines two techniques for these approaches as, firstly that consumers are asked to evaluate a series of hypothetical and real products, defined in terms of their features; and secondly that consumers are asked to view a series of competing products and select one or, in some cases, more than one. He posits that these choice-based approaches are based on a more realistic task that consumers perform every day; the task of choosing a product from among a group of competitors. Harmonizing these positions therefore, Zinas and Jusan [12] propose an extension to MEC model for housing choice and preference in a hypothetical research setting as in Fig. 3

This extended MEC model proposes that a set of housing attributes are profiled in a questionnaire or multi-media tool(s) and presented to target respondents to elicit their choices through a selection process. Thereafter, this choice information is fed into the laddering tool for the laddering one-on-one interviews to elicit the linkages of consequences of the chosen housing attributes, and the personal values that necessitated these choices. The research relationship between laddering interview and the variables of consequences and user values in the model is a kind of "pendulum-swing" type as outlined in the traditional MEC model. The sampling processes of the respondents in both stages depends largely on the researcher's investigative interest, which he must establish within a certain sampling criteria determined by him.

\subsection{Housing Preference and Choice Measurement Models}

Timmermans et al. [10] methodological works presented broadly two measurement housing choice



Fig. 3 Proposed extension to MEC model for housing choice and preference [12]. 
and preference modeling approaches as: the revealed models of housing choice and the stated models of housing preference and housing choice. Both models have the following common assumptions: firstly, they assume that houses or residential environments can be described and qualified in terms of a set of attribute levels; secondly, they assume that individuals or households derive some part-worth utility from each of the attribute levels; and thirdly, they assume that individuals combine their part-worth utility according to some rule to arrive at an overall preference or choice $[9,10]$. However, according to Coolen and Hoekstra [8], these models contrast with the laddering measurement approach. Often, the aim of studying housing choices and preferences using these models is to identify the nature and strength of the relationship of the probability of choosing a particular housing type and a set of spatial and socio-demographic variables. According to research, these studies are primarily descriptive [44-47], which have increased the understanding of housing markets substantially.

The revealed models are based on observational data of households' actual housing choices [8, 9]; while the stated models are based on intended housing choices or hypothetical housing choices [8]. We will only highlight the stated models in this paper. For detail study of these models refer Timmermans et al. [10], Molin et al. [40].

Stated housing preferences have been studied extensively [48]. In spite of this assessment, Coolen et al., [19] allude that researches in housing preferences paid little attention to underlying motivational factors as goals, attitudes and values. This is where MEC model is relevant to measure these intrinsic and abstract variables. Stated preference approaches can be further classified and distinguished into algebraic and non-algebraic methods. The algebraic methods use a mathematical expression to relate the utility of attribute levels to measure of overall preference, while the non-algebraic methods are alternatives to algebraic models to handle more complicated if-then structures which algebraic models by definition cannot represent [10]. Fig. 4 illustrates the conceptual framework of these models.

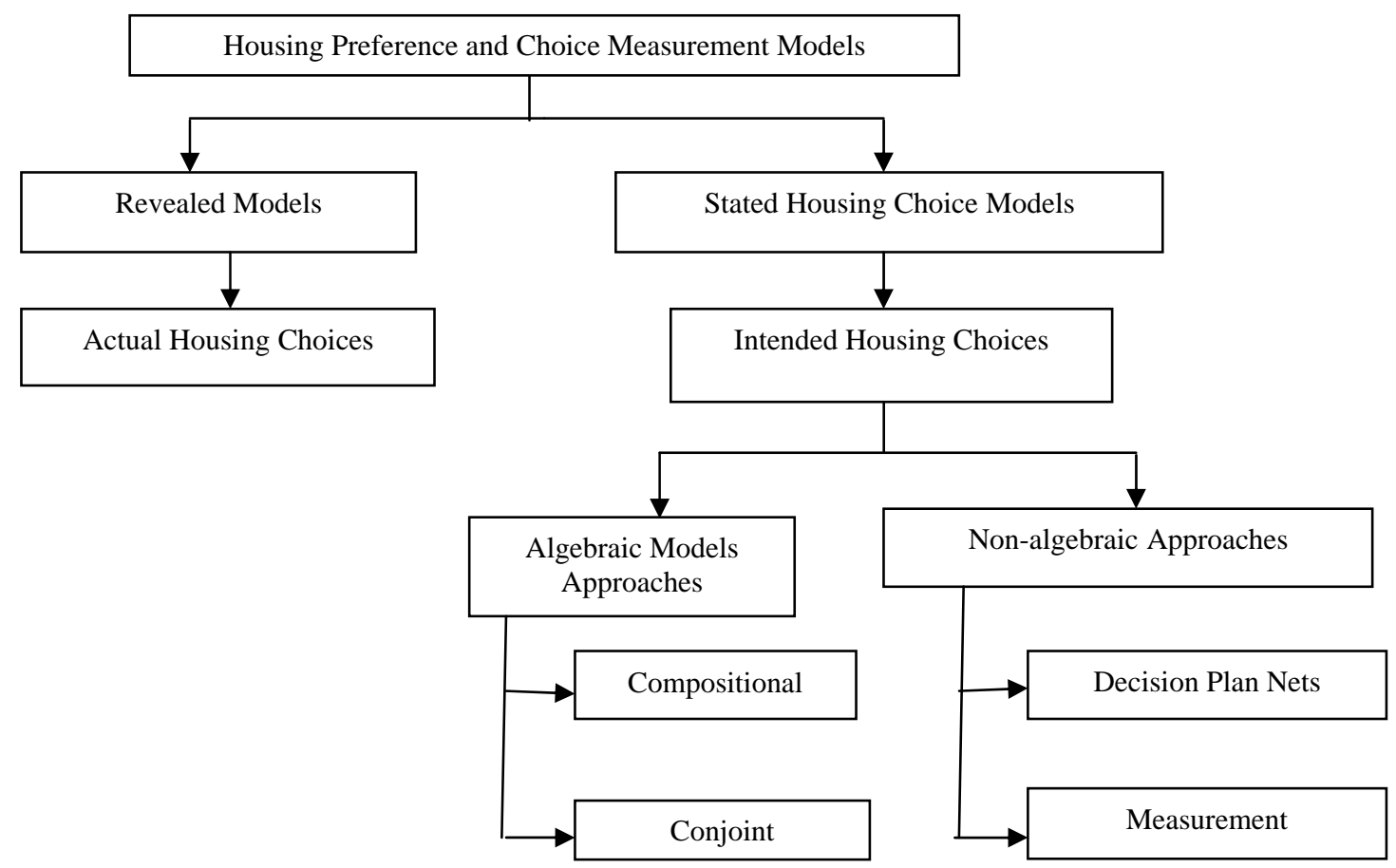

Fig. 4 Conceptual structure of housing choice \& preference models [11]. 


\section{Adaptation and Application of MEC in Housing Research}

In this section, we highlight the applicability of MEC in housing research, by reviewing in brief previous works that utilized MEC model in their housing research. Mahmud posits that the adaptation and application of MEC model in housing research is still at its early stage, as a result literature on this area is scarce. He adjudges the works of Coolen and Hoekstra [8] on housing preference in the Netherlands as probably the first attempt to apply MEC research method to measure the appropriateness of the design of the built environment. Jusan [7, 39], while following the footsteps of Coolen and Hoekstra [8] used the MEC model as a research tool to test and measure housing personalization in Malaysia. These studies, Jusan and Coolen and Hoekstra [7, 8, 39] are probably the pivot pioneering works that applied MEC model as a tool in housing research. However, prior to these studies, the methodological works of Timmermans et al. [10] and Molin et al. [40] on housing choice processes and predicting consumer response to new housing, respectively, probably set up the stage for doing housing research with the application of the MEC model. The studies of Coolen and Hoekstra [8] utilized one of the methodological models presented in Timmermans et al. studies [10]. Although Timmermans et al. [10] did not specifically make reference to MEC in their work, it is clear that the underlying principles for their works were embedded in MEC model as the general framework. Moreover, the basic constructs or variables of MEC make up the basic components of the housing choice and preference measurement models-the revealed and stated models-presented by Timmermans et al. [10].

Both Jusan [7, 39, 49] and Coolen and Hoekstra [8] studies found the MEC model as an authentic tool for housing research. Jusan [7, 39, 49] used MEC model to explore people's behavior in changing their living environments which he describes as "housingpersonalization” in Malaysia. He found that housing users' personal design expectations have been a direct influence on the physical modification of their houses. On the other hand, Coolen and Hoekstra [8] pilot study on housing preference in the Netherlands which centered on people's behavior in choosing living environment, found that values are one of the determinants in housing choice and selection. Based on their findings, these researchers make these concluding remarks: Jusan [7] states that the application of MEC model for identifying users housing expectations will be useful in housing design process, and can be tested in housing design towards a more suitable living environment, hence good housing. Coolen and Hoekstra [8] posit that housing choice and preference behavior is also value-oriented and goal-directed behavior like any other product choice behavior.

\section{Conclusion and Discussion}

In this paper, we have explored from various literatures the Means-End Chain model as a tool, and its applicability to housing research, although its initial intentions and purposes were geared towards merchandized consumer goods and services research. We also explored the relationship between an individual's choice and preference behavior as it relates to housing attributes in the MEC model, which conceptual framework was also presented. Although the applications of the MEC model in housing research and its attendant linkages is still at its relatively infant stage, it is found from the few studies conducted, that using the MEC model as a tool has been very positive in performance and proved that MEC can be relied upon for housing research. Since the application of MEC is still at an early stage in housing research, it then presupposes that a lot and vigorous housing research needs to be carried out with MEC research model.

Laddering, which is unquestionably a useful technique for identifying the relevant attributes and life 
values in a particular product domain, and for studying the complexities of consumers' cognitive structures with respect to that domain, can fruitfully be combined with a questionnaire technique in eliciting responses from housing users to establish their choice behaviors. It could also be used with any of the other models presented in this paper. In this respect, we have proffered and presented a proposed extension to the traditional MEC model for hypothetical housing research.

The few researches conducted have been done mostly in the area of spatial configuration of the housing product-the house. The house which is made of diverse and heterogeneous attributes requires that other aspects of the housing attributes need to be researched into, and the attendant motivations for the housing user in choosing a set of housing attributes over and above alternative sets of housing attributes. Besides the spatial configuration attributes (e.g., the size or number of rooms) of the house, there are other attributes of the house like concealed attributes (e.g., reinforcements, substructure, beams, columns, etc.), exposed attributes (e.g., fittings, finishes, etc.), elemental components (e.g. windows, doors, etc), roof style (e.g., gabled, hipped, flat, etc), and aesthetics attributes (e.g., the treatment of the external features of the building), that require further research. Spatial dimensional attributes (e.g., the sizes of the rooms, both horizontal and vertical) of housing is also another area that requires further research. For each of these attributes, there are motivational reasons for the preference and choice behavior of the user in deciding for each set of preferred attributes alternatives.

The MEC research model is a good research tool that will divulge the hidden choice-behaviors. MEC has been found to be very valid, reliable and potent in performance for measuring both objective and subjective aspects of housing environments and users intrinsic choice behaviors respectively. In summary, MEC is found to be a very vital and useful research tool; therefore we strongly recommend the use of MEC model as a tool for housing research.

\section{Acknowledgement}

The continuous support of the management of Universiti Teknologi Malaysia (UTM) has made this work possible.

\section{References}

[1] K. G. Grunert and S. C. Grunert, Measuring subjective meaning structures by the laddering method: Theoretical considerations and methodological problems, International Journal of Research in Marketing (12) (1995) 209-225.

[2] R. G. M. Pieters, J. B. E. M. Steenkamp and M. Wedel, Issues in Means-End Chain Theory, Erasmus University, 1991.

[3] T. J. Reynolds and J. Gutman, Laddering theory, method, analysis, and interpretation, Journal of Advertising Research 28 (1988) 11-31.

[4] P. Valette-Florence and B. Rapacchi, Improvements in means-end chain analysis: Using graph theory and correspondence analysis, Journal of Advertising Research 31 (1991) 30-45.

[5] J. Gutman, A means-end chain model based on consumer categorization processes, Journal of Marketing 46 (1982) 60-72.

[6] A. A. I. Tania, Modesto Veludo-de-Oliveira and Marcos Cortez Campomar, Discussing laddering application by the means-end chain theory, The Qualitative Report 11 (4) (2006) 626-642.

[7] M. M. Jusan, Identification of user's expectations in mass housing using means-end chain research model, Journal Alam Bina 9 (4) (2007) 1-19.

[8] H. Coolen and J. Hoekstra, Values as determinants of preferences for housing attributes, Journal of Housing and Built Environment 16 (2001) 285-306.

[9] M. A. Orzechowski, Measuring Housing Preferences Using Virtual Reality and Bayesian Belief Networks, Eindhoven: Technische Universiteit Eindhoven, 2004.

[10] H. Timmermans, Molin Eric and Noorwijk van Lily, Housing choice processes: Stated versus revealed modeling approaches, Netherland Journal of Housing and the Built Environment 9 (3) (1994) 215-227.

[11] B. Z. Zinas and M. M. Jusan, Choice behaviour of housing attributes: Theory and measurement, Asian Journal of Environment-Behaviour Studies 1 (2) (2010a) 1-17.

[12] B. Z. Zinas and M. M. Jusan, Theoretical framework of means-end chain model for measuring housing environment choice and preference, in: 4th International Conference on Built Environment in Developing Countries, USM Penang-Malaysia, 1-2 Dec., 2010. 
[13] B. Weijters and S. Muylle, A Means-End-Chain Analysis of Pub Visits in Belgium, Vlerick Leuven Gent Management School, 2008.

[14] E. Kaciak and C. W. Cullen, Analysis of means-end chain data in marketing research, Journal of Targeting, Measurement and Analysis for Marketing (15) (2006) 12-20.

[15] M. J. Rokeach, Beliefs, Attitudes and Values, San Francisco: Jossey Bass, 1968.

[16] D. Yankelovich, New Rules, New York: Random House, 1981.

[17] M. M. Boer de and B. McCarthy, Means-End Chain Theory Applied to Irish Convenience Food Consumers, Cork: National University of Ireland, 2004.

[18] G. Rugg, M. Eva, A. Mahmood, Rehman S. Andrews and S. Davies, Eliciting information about organizational culture via laddering, Information Systems Journal 12 (1) (2002) 215-229.

[19] H. Coolen, P. Boelhouwer and V. D. Kees, Values and goals as determinants of intended tenure choice, Journal of Housing and Built Environment 17 (2002) 215-236.

[20] T. J. Reynolds and D. Whitlark, Applying laddering data to communications strategy and advertising practice, Journal of Advertising Research 35 (1995) 9-16.

[21] J. Meesters, Residents' Meanings of Specific Architectural and Urban Design Features, Delft: Delft University of Technology, 2005.

[22] J. Olson and T. Reynolds, Understanding consumer's cognitive structures: Implications for advertising strategy, in: L. Percy and A. Woodside (Ed.), Advertising and Consumer Psychology Lexington, MA: Lexington Books, 1983, pp. 77-90.

[23] G. Botschen, E. M. Thelen and R. Pieters, Using means-end structures for benefit segmentation and application to services, European Journal of Marketing 33 (1-2) (1999) 38-58.

[24] T. L. Lorimer and E. L. Doris (Eds.), The New Webster's Dictionary of the English Language (International ed.), New York: Lexicon Publications Inc., 1995.

[25] C. E. Gengler, M. S. Mulvey and J. E. Oglethorpe, A means-end analysis of mother's infant feeding choices, Journal of Public Policy and Marketing 18 (2) (1999) 172-188.

[26] M. Vriens and F. T. Hofstede, Linking attributes, benefits, and consumer values, Journal of Advertising Research 12 (3) (2000) 4-10.

[27] C. Lin, Attribute-consequence-value linkages: A new technique for understanding customer's product knowledge, Journal of Targeting Measurement and Analysis for Marketing 10 (2002) 339-352.

[28] A. Dibley and S. Baker, Uncovering the links between brand choice and personal values among young British and Spanish girls, Journal of Consumer Behaviour 1 (1) (2001) 77-93.

[29] S. H. Schwartz, Are there universal aspects in the structure and contents of human values? Journal of Social Issues 50 (1994) 19-45.

[30] S. H. Schwartz, Universal in the content and structure of values: Theoretical advances and empirical tests in 20 countries, in: Advances in Experimental Social Psychology, San diego: Academic Press, 1992.

[31] M. Rokeach, The Nature of Human Values, New York: Free Press, 1973.

[32] M. Blaauboer and Clara H. Mulder, Residential choice and attitudes towards family and work, Amsterdam: University of Amsterda, 2007.

[33] A. I. A. Costa, M. Dekker and W. M. F. Jongen, An overview of means-end theory: Potential application in consumer-oriented food product design, Trends in Food Science \& Technology (15) (2004) 403-415.

[34] M. Hawlev, Laddering: A research interview technique for uncovering core values, Research That Works, 2009.

[35] D. Hinkle, The change of personal constructs from the viewpoint of theory of construct application, unpublished Doctoral Dissertation, Columbus, Ohio: Ohio State University, 1965.

[36] D. Bannister and J. M. M. Mair, The Evaluation of Personal construct, London: Academic Press, 1968.

[37] B. Wansink, Using laddering to understand and leverage a brand's equity, Qualitative Market Research: An International Journal 6 (2) (2003) 111-118.

[38] C. E. Gengler and T. Reynolds, Consumer understanding and advertising strategy: analysis and strategic translation of laddering data, Journal of Advertising Research 35 (4) (1995) 19-32.

[39] Jusan M. Mohd, Means end chain, person environment congruence and mass housing design, Open House International 35 (3) (2010b) 77-86.

[40] E. Molin, Oppewal Harmen and Timmermans Harry, Predicting consumer response to new housing: A stated choice experiment, Netherland Journal of Housing and the Built Environment 11 (3) (1996) 297-311.

[41] W. Adamowicz, J. Louviere and J. Swait, Introduction to attribute-based stated choice methods, Alberta: National Oceanic and Atmospheric Administrationo, 1998.

[42] J. Abley, Stated preference techniques and consumer decision making: new challenges to old assumptions, Edmonton: National Oceanic and Atmospheric Administrationo, 1997.

[43] A. Merino-Castello, Eliciting consumers preferences using stated preference discrete choice models: Contingent ranking versus choice experiment, Empresa Universitat Pompen Fabra, Ramon Trias, Barcelona, 2003. 
[44] J. J. Louviere and H. J. P. Timmermans, Stated preference and choice models applied in recreation research: A review, Leisure Sciences (12) (1990) 9-32.

[45] H. J. P. Timmermans and L. van Noortwijk, Context dependencies in housing choice behavior, Environment and Planning A (27) (1995) 181-192.

[46] F. M. Dieleman, Modeling housing choice, Netherlands Journal of Housing and the Built Environment (11) (1996) 201-207.
[47] D. Wang and J. Li, Handling large numbers of attributes and/or large numbers of levels in conjoint experiments, Geographical Analysis 34 (2002) 350-362.

[48] C. H. Mulder, Housing choice: Assumption and approaches, Netherland Journal of Housing and the Built Environment 11 (3) (1996) 209-232.

[49] Jusan M. Mohd, Rénovation for Personalization-A Development Arm of Sustainable Housing, UTM Press, Johor Bahru, Malaysia, 2010a. 